\title{
Saúde e confiança organizacional: estudo em uma indústria de laticínios no sudoeste do Paraná
}

\author{
Andresa Rosa de Lima Graduada em Administração. Universidade Estadual do Oeste do Paraná (UNIOESTE) - Brasil. \\ andresa vere@hotmail.com. \\ Adilson Carlos da Rocha Doutor em Administração. Universidade Estadual do Oeste do Paraná (UNIOESTE) - Brasil. \\ adilson28@hotmail.com. \\ Gilberto Francisco Ceretta Doutor em Administração. Universidade Estadual do Oeste do Paraná (UNIOESTE) - Brasil. \\ gilbertoceretta@gmail.com.
}

\section{RESUMO}

O presente estudo teve como objetivo analisar a saúde e a confiança organizacional de acordo com a percepção dos funcionários em uma empresa com operações na indústria de laticínios na região Sudoeste do Paraná. 0 estudo teve uma abordagem quantitativa, com características de pesquisa descritiva. A amostra para o estudo foi constituída por 66 funcionários, os quais participaram do estudo por conveniência e aceitação, 0 que correspondeu $60 \%$ da população estimada. Considerando os resultados ap resentados para os do is fatores que compõem a EPSaO, 84,8\% dos pesquisados indicaram que não percebem que existe ou tem dúvidas quanto a capacidade de estimular compartilhamento dos objetivos organizacionais, e outros $71,3 \%$ da mesma forma não perceberam que existe ou tem dúvidas quanto a flexibilidade nas políticas e procedimentos organizacionais na adaptação às demandas do ambiente externo. Nos resultados para as dimensões que compõem a ECEO, a dimensão que apresentou maior percentual para percepção positiva foi a dimensão padrões éticos com $34,8 \%$, já para a dimensão normas relativas à demissão de empregados os pesquisados indicaram percepção negativa representada por $80,3 \%$ dos pesquisados.

Palavras-chaves: Saúde organizacional. Confiança organizacional. Laticínios.

\section{Health and organizational reliability: study in a dairy industry in the southwest of Paraná}

\begin{abstract}
The present study aimed to analyze health and organizational reliability according to the perception of employees in a company with operations in the dairy industry in the Southwest Region of Paraná. The study had a quantitative approach with descriptive research features. The sample for the study consisted of 66 employees, who participated in the study for convenience and acceptance, which corresponded to $60 \%$ of the estimated population. Considering the results presented for the two factors that compose EPSaO, $84.8 \%$ of respondents indicated that they do not perceive doubts about the ability to stimulate sharing of organizational goals, and another $71.3 \%$ did not realize there to be doubts as to the flexibility in the organizational policies and procedures in the adaptation to the demands of the external environment. In the results for the dimensions that make up the ECEO, the dimension that presented the highest percentage for positive perception was the ethical standards dimension: $34.8 \%$. However, for the regulations related to the dismissal of employees the respondents indicated a negative perception represented by $80.3 \%$ of respondents.
\end{abstract}

Keywords: Organizational health. Organizational reliability. Dairy products. 


\section{INTRODUÇÃO}

Saúde organizacional e confiança na organização são temas importantes no âmbito da gestão organizacional, pois, com a globalização e a alta competitividade de mercado, associadas a fatores econômicos e tecnológicos, os quais não podem mais ser considerados suficientes para garantir uma posição sustentável por parte da organização. Dessa forma, os trabalhadores passaram a ter um papel fundamental para desempenho do trabalho, e para o alcance das metas com resultados satisfatórios.

A preocupação com o ser humano em seu ambiente de trabalho e a relação trabalhador versus organização tem sido estudada de forma constante nos campos acadêmicos e organizacionais. 0 construto de saúde organizacional surgiu nos anos de 1950, vinculado com a efetividade organizacional, sendo que a literatura admite a saúde organizacional, como sendo uma noção "expandida" da efetividade organizacional. Sendo assim, a saúde organizacional seria um conceito mais amplo contemplando as necessidades dos clientes, dos fornecedores, dos acionistas e dos membros da comunidade que estão ligados. A organização que propicia saúde a seus empregados e à comunidade é uma organização saudável.

Além dos aspectos que envolvem a saúde organizacional, outro fator importante no âmbito do trabalho é a confiança organizacional, a confiança facilita a troca e compartilhamento de informações e aumenta a disposição das pessoas para expressar suas opiniões.

Tem crescido muito nos últimos anos os estudos no âmbito de saúde e confiança organizacional, pois parece ser essencial conhecer a forma como acontece a relação de confiança entre o empregado e a organização onde este trabalha, bem como a saúde organizacional evidenciada pela organização.

Diante desses aspectos importantes que envolvem os temas "saúde" e "confiança" organizacional e o interesse em ampliar o conhecimento sobre esses construtos, elaborou-se a questão norteadora para este estudo. Como se apresenta a saúde organizacional e o grau de confiança na organização, de acordo com a percepção dos trabalhadores em uma organização industrial?

A partir desta questão o presente estudo teve como objetivo analisar a saúde e a confiança organizacional de acordo com a percepção dos funcionários em uma organização com operações na indústria de laticínios na região Sudoeste do Paraná.

\section{Saúde organizacional}

Surgiram na década de 1950, as primeiras proposições sobre saúde organizacional. Aquela organização que apresentar adaptabilidade, teste da realidade e também 0 senso identidade seria a organização saudável, pois a adaptabilidade refere-se a uma característica que acaba coincidindo com a capacidade de resolver problemas que depende da flexibilidade organizacional, ou seja, que é a liberdade de aprender por meio da existência, de mudar em simultaneidade com as circunstâncias internas e externas. Já o teste de realidade indica para a habilidade organizacional para receber, conhecer e interpretar de forma correta as condições do meio ambiente que são relevantes para o funcionamento da organização. 0 senso de identidade está relacionado com o conhecimento que a organização tem sobre o que ela é, quais suas metas, e o que deve fazer (GOMIDE JÚNIOR; FERNANDES, 2008).

De acordo com Gomide Júnior e Fernandes (2008), nos estudos de Schein (1965) foi proposto um quarto critério, sendo esse o estado de integração indivíduo-organização, o qual refere-se ao grau de harmonia entre os sistemas da organização. Destacam ainda o estudo de Mello (1978), no qual desmembraram os quatro critérios em sete, sendo eles: identidade, orientação, sensibilidade realista, criatividade, flexibilidade, integração e por fim, reservas de energias.

Nos estudos de Jaffe, publicados em 1995, houve uma proposta de redefinição de saúde organizacional, como uma ação ampliada de efetividade, ele considera que a organização tem que ser saudável para si mesma pelo crescimento, ter coerência e adaptabilidade, pois uma organização saudável influenciará a saúde de seus membros, então desta maneira a organização, para oferecer aos colaboradores um local de trabalho saudável, para os seus sócios pelo aumento dos valores de suas ações; para os seus 
fornecedores e aos seus clientes, oferecer bons valores e também bons serviços, e para a comunidade sempre ter responsabilidade econômica e social (GOMIDE JÚNIOR; FERNANDES, 2008).

\subsection{De efetividade a saúde organizacional: a construção dos conceitos}

De acordo com Oliveira e Gomide Junior (2009), em 1957 a efetividade organizacional foi definida como sendo a extensão em que a empresa, como sistema social, alcança seus objetivos sem incapacitar os meios e recursos e, também, sem gerar tensão entre seus membros.

Alguns critérios de efetividade receberam críticas, Argutis 1958 questionou sobre os critérios baixa rotatividade e absenteísmo, produtividade elevada, alta lealdade dos empregados, sentimentos positivos e recíprocos entre supervisores e empregados. Por não se referirem a natureza do sistema em si, Schein 1965 destacou a efetividade organizacional como a capacidade que a empresa tem para sobreviver, de se adaptar, e de se manter e crescer independente das particulares funções desempenhadas (OLIVEIRA; GOMIDE JUNIOR, 2009).

Segundo Oliveira e Gomide Junior (2009) na década de 1980 os critérios da efetividade foram estruturados e classificados em modelos, e essas tentativas de classificação deste construto refletem nos acordos quanto em desacordos relativos ao assunto. Quem realizou o estudo de classificação dos critérios de efetividade e modelos foi Quim Rolvbaugh em 1983, o estudo foi dividido em duas etapas. Sendo a primeira de caráter exploratório que não pertencessem ao nível organizacional de análise. A segunda etapa é outro grupo de autores que avaliaram similaridade entre possível par dos dezessete critérios remanescentes em uma escala de um a sete, ou seja, de semelhante a muito diferente. Em seguida foi realizada uma análise multidimensional e foram classificados os critérios restantes em três dimensões de valor da seguinte maneira: a primeira dimensão é a do foco organizacional, a segunda dimensão é a estrutura organizacional e a terceira é a dos meios e fins organizacionais.

De acordo com Oliveira e Gomide J unior (2009) os estudos do construto de efetividade organizacional contribuíram para o surgimento da saúde organizacional. Conforme Moraes (2007), os estudos de Bennis 1962 colocaram claramente a expansão da definição do conceito de efetividade organizacional, sendo introduzido na literatura, o conceito mais geral de saúde organizacional, propondo um critério múltiplo para o conceito de efetividade organizacional, envolvendo adaptabilidade, sentimento de identidade, capacidade de testar a realidade e integração de pessoas.

Segundo Moraes (2007), também foi Bennis em 1962, que fez um paralelo entre o desenvolvimento dos critérios de avaliação da saúde mental e a evolução dos padrões para a avaliação do conceito de saúde organizacional; 0 autor (Bennis) apresentou quais sejam: sendo que estes seriam as bases para o conceito de saúde organizacional, os três critérios são adaptabilidade, teste da realidade e senso de identidade.

A adaptabilidade está ligada no que se refere à capacidade de resolver problemas que dependem da flexibilidade da organização. Tendo como flexibilidade, a liberdade de se aprender por meio de experiência. A identidade pode ser vista por duas maneiras. A primeira determinação, até que ponto os objetivos da empresa são compreendidos e aceitos e a outra forma é que é apurado até onde a empresa está sendo percebida de forma verdadeira pelos funcionários. No teste de realidade, a empresa deve ter conhecimento e compreender o seu negócio no meio interno e externo, ou seja, a organização deve ter conhecimento sobre as suas limitações internas e externas (MORAES, 2007).

Moraes (2007) destaca que foi importante a definição na literatura que marcou a concepção de efetividade organizacional, foi o conceito de que a organização é um sistema considerado aberto e dinâmico, ou seja, é caracterizado por um processo de entradas (input) e saídas (output), sendo considerado, entradas a inclusão de novas pessoas na empresa, materiais e energia, e considerado como saída, os serviços pelo sistema empregador. A organização é entendida como um sistema aberto, que significa que deve ser dependente sempre do seu ambiente para a observação de seu produto e serviço, manterá a existência da organização o fornecimento necessário de entradas para os processos organizacionais e suas transformações.

Segundo Moraes (2007), a organização entendida como um sistema aberto tende a conduzir a uma maneira diferente de se pensar a efetividade organizacional. a efetividade organizacional tem como definição, 
por uma base de inputs e outputs. Moraes (2007) coloca que nos estudos de Katz e Kahn (1966) que para organização sobreviver ela depende de trocas com o ambiente social e não somente de ter lucro econômico.

\subsection{Confiança organizacional}

De acordo com Oliveira e Tamayo (2008), as pessoas buscam relações sociais que Ihes traga um sentido de segurança, pois a segurança é uma das bases da interação social. A segurança é um mecanismo que reduz a incerteza e, dessa maneira, possibilita a criação de pressupostos relativos ao comportamento futuro da outra parte que está envolvida na relação. A confiança é entendida também como um indicador de que a interação social poderá ser mantida ao longo do tempo.

Com base nos estudos de Zanini (2007), Cotta (2010) destaca a confiança como uma variável mediadora fortemente relacionada à satisfação, motivação e comprometimento dos empregados, também sugere que um estilo de gestão baseado na confiança, significa a opção pela implantação de um sistema particular de incentivos que promovam relações cooperativas baseadas em normas de reciprocidade e benefício mútuo entre os membros cooperativos.

A alternativa de um estilo de gestão baseado em confiança é uma opção estratégica pelo bom emprego de mecanismos sociais, acrescentando que as relações de confiança trabalham como sendo um importante mecanismo para a diminuição de risco comportamental dentro dos sistemas sociais. A presença da confiança entre os agentes enfraquece as oportunidades de comportamentos oportunistas e motiva as pesso as a realizarem transações sem o temor de prejuízos pessoais, oferecendo seus melhores esforços e ideias para a criação de valor econômico (COTTA, 2010; ZANINI, 2007).

De acordo com Cotta (2010), o estudo de Passuello (2006) destaca a definição de confiança por meio de três características principais, sendo elas: a vulnerabilidade, a reciprocidade e a expectativa. A vulnerabilidade refere-se quando o indivíduo, ao decidir em confiar, está de forma direta se colocando em risco, uma vez que não há como prognosticar como a outra parte agirá, colocando-se em risco de que o outro indivíduo haja de forma diferente da esperada.

A segunda característica sugerida no estudo de Passuello (2006) é a reciprocidade, a qual diz respeito, ou melhor, que corresponde à influência das interações cumulativas no aumento ou diminuição da confiança entre as partes envolvidas. De modo que repetidas interações entre os indivíduos ao longo do tempo, nas quais se confia, e os comportamentos esperados são empregados, aumentam a confiança mútua, assim quando não se prioriza a confiança abrem-se margens para a desconfiança.

A terceira e última característica é a expectativa, onde se observa que há uma forte relação com a elevação de risco ligado ao ato de confiar, uma vez que ao confiar se mantém a expectativa de que o outro aja da forma esperada reduzindo-se a apreensão so bre o agir oportuníssimo (PASSUELLO, 2006).

Nos estudos de Hosmer (1995), a definição de confiança está alicerçada na expectativa dos autores envolvidos em uma relação ou troca econômica entre pessoa, grupo, organização e quanto a comportamentos moralmente aceitos, baseados em princípios da análise ética. Considerou a troca de bens possível na presença da confiança, bem como essencial a confiança nas relações comerciais (COTTA, 2010).

Cotta (2010) ressalta que a confiança no mundo dos negócios dirige para o favorecimento do processo gerencial, uma vez que busca a identificação e agrupamento de fatores que formam a confiança no trabalho e auxiliam a gestão da confiança pelos gerentes nas empresas.

Para Zanini (2007), muitas relações econômicas fluem através da confiança entre as partes envolvidas, e que a confiança é um fenômeno social que só recentemente vem sendo inserido em estudos de economia, sociologia e gestão organizacional. É importante, pois uma vez que contribui no gerenciamento, intensifica como, por exemplo, a troca de conhecimento e otimização das tarefas.

Para Zanini, Lusk e Wolff (2009) a existência da confiança em ambientes organizacionais não é substituível como mecanismo social, a sua eficiência é superior a qualquer sistema que tente substituí-la. Em uma sociedade do conhecimento, onde a inovação, a qualidade e o trabalho em equipe são diferenciais competitivos, é a base para a formação do valor econômico. 
Segundo Oliveira e Tamayo (2008), a confiança está ligada com a ética e a moral, sendo assim, os indivíduos formam juízos sobre o que acreditam que é correto e ao que é errado. A moral denominada ética das virtudes, sendo a virtude a capacidade ou potência moral. É preciso delimitar o nível de análise distinguindo-o dos demais para entender a relação de confiança estabelecida entre o empregado e a sua organização. A confiança interpessoal tem por caraterística, contato face a face entre os envolvidos.

$\mathrm{Na}$ confiança organizacional, com conhecimento do papel a ser desempenhado por um indivíduo e não por suas habilidades, motivos e intenções particulares. As regras da organização, que são compartilhadas pelos indivíduos em relação ao comportamento tido como apropriado é outra base da confiança, pois diz respeito aos requisitos legítimos do sistema. Com as regras especificadas e conhecimento tácito podem ser combinados de modo a produzirem um alto nível de confiança, possibilitando ao colaborador fazer inferências a respeito do comportamento de outro indivíduo (OLIVEIRA; TAMAYO, 2008).

Papéis e regras pelas suas características podem ser interpretados como bases especificas da confiança na organização. Cotta (2010) ressalta que há diferença entre confiança interpessoal e confiança de instituições, sug erindo que essa diferença permite fundamentos teóricos específicos a serem empregados nos estudos.

\section{MÉTODO DO ESTUDO}

Este trabalho tem uma abordagem quantitativa. Para levantamento de dados foram utilizados dois questionários com questões estruturadas, com uma escala de resposta tipo Likert de 5 pontos. Os dados obtidos serão tabulados e analisados com a aplicação de técnicas de estatística descritiva.

O estudo apresenta como característica, uma pesquisa descritiva, que observa, registra, analisa e correlaciona fatos sem manipulá-los, assim procura descobrir com a maior precisão possível, a frequência com que o fenômeno ocorre, sua relação e conexão com outros, sua natureza e suas características, e também busca conhecer as diversas situações e relações que ocorrem na vida social, política, econômica e demais aspectos do comportamento humano (CERVO; BERVIAN; SILVA, 2007).

Para este estudo, estimou-se uma população de 110 funcionários, correspondendo ao quadro atual de empregados da organização, objeto desse estudo. A técnica de coleta utilizada para a constituição da amostra foi a de levantamento, ou survey, essa técnica é empregada para identificar a estratégia de pesquisa (MARTINS; THEÓPHILO, 2009).

Para a coleta de dados foram utilizados dois instrumentos compostos por escalas psicométricas (ECEO e EPSaO). Tratam-se de instrumentos de pesquisa constituídos por uma escala tipo Likert de cinco opções de respostas, que permite aos funcionários responder cada questão em graus variados, sendo as respostas de um a cinco, sendo: 1 discordo totalmente, 2 discordo, 3 nem concordo e nem discordo, 4 concordo, 5 concordo totalmente.

A coleta de dados deu-se no mês de agosto de 2016 na organização, em horário trabalho, onde 66 funcionários responderam o instrumento de pesquisa, o que representou $60 \%$ da população estimada.

Os dados foram tratados com aplicação de técnicas de estatística descritiva e inferencial. Segundo Dancey e Reidy (2006), as estatísticas são importantes formas de descrever, relacionar e comparar as variáveis estudadas. A partir dos dados coletados foram aplicadas técnicas de estatística bivariada e multivariada (análise de correlação, testes de hipóteses, entre outras). A definição das técnicas utilizadas baseou-se no comportamento dos dados observando os pressupostos elencados pela literatura.

\subsection{Construção e avaliação da escala EPSAO}

A Escala de Percepção de Saúde Organizacional - EPSaO, foi criada com o propósito de averiguar a percepção dos empregados a respeito da saúde da organização. Os itens que compõe a escala foram desenvolvidos com base nos critérios de Saúde Organizacional apontados por Bennis (1962), Shein (1965), e Fordyce e Weil (1971) e também foram baseados em uma primeira proposição de validação de Gomide Jr. e colaboradores (GOMIDE JUNIOR; FERNANDES, 2008). 
A EPSaO é composta por dois fatores, sendo: (I) integração de pessoas e equipes; e (ii) flexibilidade e adaptação demanda externas. 0 Quadro 1 apresenta os fatores, suas definições e os respectivos itens do instrumento de pesquisa.

Quadro 1 - Denominação, Definições, Itens da EPSaO

\begin{tabular}{|l|l|c|}
\hline \multicolumn{1}{|c|}{ Denominação } & \multicolumn{1}{|c|}{ Definiçães } & \multicolumn{1}{|c|}{ Itens } \\
\hline \multirow{3}{*}{ Integração de pessoas e equipes } & $\begin{array}{l}\text { Crenças do empregado de que organização é } \\
\text { capaz de estimular compartilhamento dos } \\
\text { objetivos organizacionais a integração de seus } \\
\text { membros as suas equipes de trabalho. }\end{array}$ & $\begin{array}{r}1,2,3,4,5,6,7,1 \\
8,9,11,12, \\
13,15,17,18, \\
19,20,21\end{array}$ \\
\hline \multirow{2}{*}{$\begin{array}{l}\text { Flexibilidade e adaptação, } \\
\text { demanda externas }\end{array}$} & $\begin{array}{l}\text { Crenças do empregado de que a organização } \\
\text { possui políticas e procedimentos de trabalho } \\
\text { flexíveis e voltados para a adaptação da } \\
\text { organização às demandas do ambiente externo. }\end{array}$ & $\begin{array}{c}16,22,23,24,25, \\
26,27\end{array}$ \\
\hline
\end{tabular}

Fonte: Adaptado de Gomide Jr. e Fernandes (2008).

Quanto à forma de aplicação da escala de percepção de saúde organizacional, Gomide Junior e Fernandes (2008), argumentam que a mesma pode ser realizada de forma individual ou coletiva, sendo importante assegurar que o ambiente da aplicação seja um ambiente tranquilo e confortável, e o tempo para a sua aplicação não sendo limitado.

De acordo com Gomide J unior e Fernandes (2008), a EPSaO é composta por dois fatores, sendo assim, o cálculo dos escores médios deverá ser feito para cada um dos fatores. Dessa forma, o cálculo do escore médio da EPSaO será obtido somando os valores assinalados pelo respondente em cada um dos itens que integra cada fator, e dividindo-se este valor pelo número de itens do fator.

$\mathrm{Na}$ interpretação dos resultados, deve-se considerar que quanto maior o valor do escore fatorial médio, maior é a percepção do respondente de que a organização empregadora apresenta a característica contemplada naquele fator. Médias fatoriais entre 1 e 2,9 tendem a indicar que o funcionário não percebe a característica enunciada pelo fator, médias entre 4 e 5 indicam que o colaborador percebe a característica enunciada, enquanto médias entre 3 e 3,9 sugerem uma dúvida do respondente quanto a presença daquela característica enunciada pelo fator.

\subsection{Construção e validação da ECEO}

Segundo Oliveira e Tamayo (2008), a Escala de Confiança do Empregado na Organização - ECEO tem por objetivo medir quanto o empregado acredita que pode confiar na empresa que trabalha. Trata-se de uma medida multidimensional composta por cinco dimensões: (i) promoção do crescimento do empregado; (ii) solidez organizacional; (iii) normas relativas à demissão de empregados; (iv) reconhecimento financeiro organizacional; e (v) padrões éticos. 0 Quadro 2 apresenta as denominações, definições dos componentes e itens integrantes da ECEO.

Quadro 2 - Denominações, Itens Integrantes da ECEO

\begin{tabular}{|c|c|c|c|}
\hline Denominações & Definiçōes & $\begin{array}{c}\mathbf{N}^{\circ} \\
\text { itens }\end{array}$ & Itens \\
\hline $\begin{array}{l}\text { Promoção do } \\
\text { crescimento do } \\
\text { empregado }\end{array}$ & $\begin{array}{l}\text { Incentivo ao crescimento profissional dos empregados por meio } \\
\text { de alternativas concretas e reais propostas pela organização, } \\
\text { permitindo aos colaboradores prever seu crescimento naquele } \\
\text { contexto de trabalho. }\end{array}$ & 5 & $\begin{array}{l}7,10 \\
12,17 \\
19\end{array}$ \\
\hline $\begin{array}{l}\text { Solidez } \\
\text { organizacional }\end{array}$ & $\begin{array}{l}\text { Refere-se à firmeza, à estabilidade financeira da organização cujos } \\
\text { reflexos são o cumprimento de suas obrigações financeiras com }\end{array}$ & 5 & $\begin{array}{r}4,13, \\
15,18,\end{array}$ \\
\hline
\end{tabular}




\begin{tabular}{|l|l|c|c|}
\hline & $\begin{array}{l}\text { os empregados, o pagamento de salário pontualmente, a } \\
\text { perspectiva de um futuro próspero, bem como a capacidade de } \\
\text { superar crises econômicas ocasionadas por planos } \\
\text { governamentais e mudanças do mercado. }\end{array}$ & 21 \\
\hline $\begin{array}{l}\text { Normas relativas à } \\
\text { demissão de } \\
\text { empregados }\end{array}$ & $\begin{array}{l}\text { Presença ou ausência de normas organizacionais definidas para } \\
\text { demissão de empregados, permitindo, ou não ao empregado } \\
\text { prever sua permanência na organização. }\end{array}$ & 6 & $\begin{array}{c}11,14, \\
\text { Os esforços do empregado são reconhecimento e valorização de }\end{array}$ \\
\hline $\begin{array}{l}\text { Reconhecimento } \\
\text { financeiro } \\
\text { organizacional }\end{array}$ & $\begin{array}{l}\text { forma financeira, principalmente, pormeio do salário. A concessão } \\
\text { de aumento salarial é percebida como uma das manifestaçães de }\end{array}$ & 5 & 23 \\
\hline $\begin{array}{l}\text { reconhecimento por parte da organização. Esse reconhecimento } \\
\text { financeiro beneficia ambas as partes. }\end{array}$ & 22,25, \\
\hline Padrões éticos & $\begin{array}{l}\text { Refere-se a princípios éticos como honestidade, igualdade, } \\
\text { transparência da organização ao divulgar informações } \\
\text { responsabilidade, manutenção de compromissos e respeito. Tais } \\
\text { princípios orientam a relação da organização com seus clientes e } \\
\text { empregados ao procurar não prejudicar aqueles com os quais se } \\
\text { relaciona. }\end{array}$ & 7 & 28 \\
\hline
\end{tabular}

Fonte: Adaptado de Gomide Jr. e Fernandes (2008).

A aplicação da ECEO pode ser feita de forma individual ou coletiva, deve-se cuidar para que os indivíduos respondentes tenham entendido as instruções e o modo de assinar as suas respostas, além de o tempo da aplicação da ECEO ser livre.

O cálculo do escore médio da ECEO é obtido somando-se os valores indicados pelo respondente dentro dos parênteses e dividindo-se essa somatória pelo número de itens de cada fator definido. Dessa maneira obtêm-se um valor que deverá situar-se entre um e cinco. Os itens assinados com asterisco deverão ter uma pontuação invertida antes de se proceder aos cálculos do escore médio. Se o respondente marcou um, será invertido para cinco, assim sucessivamente conforme indicação: um será invertido para cinco; dois será invertido para quatro; três será mantido para três; quatro será invertido para dois e cinco será invertido para um.

A interpretação dos resultados obtidos deverá considerar que quanto maior for o valor do escore médio, mais o respondente demonstra sua concordância com o conteúdo avaliado por um dado fator.

\section{APRESENTAÇÃO E ANÁLISE DOS DADOS}

A organização onde este estudo se desenvolveu foi fundada em 24 de dezembro de $1995 \mathrm{com}$ a Associação dos Produtores Rurais (APRUAL) da comunidade de Alto Alegre no município de Verê. A APRUAL tinha como objetivos fortalecer a organização social e política dos agricultores rurais.

\subsection{Características da organização}

Em 2015, a organização contava com uma estrutura moderna em tecnologia e em equipamentos para a melhor qualidade dos seus produtos, baseando-se nas mais elevadas exigências do mercado, como qualidade, higiene, sabor, praticidade e consciência ambiental, assim se solidificando nos quatro cantos do Brasil. Conta com 110 colaboradores e tem a capacidade de processar 250.000 litros/dia.

Atualmente a organização tem em seu quadro de funcionários 110 colaboradores. Participaram da pesquisa na condição de respondente, 66 funcionários. Nesta amostra, a idade mínima dos trabalhadores que colaboraram com a pesquisa é de 18 anos e 56 anos a idade do participante mais idoso. Desta amostra 30 pessoas são do gênero feminino e 36 do gênero masculino.

Quanto a distribuição na estrutura organizacional, 06 pessoas desenvolvem atividade no departamento administrativo, 47 na linha de produção e outras 13 atuam em operações externas, como setor 
de balança, e também na função de motorista. Com relação aos cargos ocupados pelos participantes da pesquisa, 5 são gerentes, 2 são líderes de setor e outros 59 atuam no operacional. Quanto ao tempo de trabalho dos funcionários na organização, a Tabela 1 apresenta o tempo de trabalho citado.

Tabela 1- Tempo de trabalho na organização

\begin{tabular}{l|l|l|c}
\hline Tempo de trabalho & Frequência & Percentual & $\begin{array}{c}\% \\
\text { Acumulado }\end{array}$ \\
\hline Menos de 1 ano & 6 & 9,1 & 9,1 \\
De 1 a 2 anos & 11 & 16,7 & 25,8 \\
De 2 a 3 anos & 13 & 19,7 & 45,5 \\
De 3 a 4 anos & 17 & 25,8 & 71,2 \\
De 4 a 10 anos & 13 & 19,7 & 90,9 \\
Mais de 10 anos & 6 & 9,1 & 100,0 \\
\hline Total & 66 & 100,0 & \\
\hline
\end{tabular}

Fonte: Dados da pesquisa (2016).

Quanto ao nível de escolaridade dos participantes do estudo, a maio ria $(81,8 \%)$ dos funcionários tem escolaridade até ensino médio completo. Este indicador apresenta-se acima do nível de escolaridade do trabalhador na indústria paranaense, pois de acordo com a CNI (2014), em 2013 a participação dos trabalhadores com pelo menos o ensino médio completo foi de $48,8 \%$ nessa indústria.

\subsection{Comportamento das variáveis utilizadas}

Os instrumentos de pesquisa utilizados, EPSaO e ECEO foram submetidos à análise de confiabilidade. A técnica estatística aplicada foi o coeficiente alfa (a) de Cronbach, o qual avalia a consistência interna dos construtos e suas variáveis intervalares que compõem o questionário aplicado em uma pesquisa. Um valor elevado de alfa (a) é frequentemente usado como prova de que os itens estão relacionados com um construto (variável latente).

Analisando o nível de confiabilidade dos questionários obtida a partir do valor do coeficiente (a de Cronbach), o qual resultou em 0,90 para a EPSaO e 0,86 para a ECEO (Apêndice B), sendo estes considerados altos, assegurando a consistência interna dos construtos mensurados.

Realizou-se também uma análise do comportamento dos dados por meio dos testes estatísticos Kolmogorov-Smirnov e Shapiro-Wilk (Apêndice B) e verificou-se que as variáveis em ambas as escalas (EPSaO e ECEO) não apresentaram uma distribuição normal. Diante dessa condição, as técnicas e os testes estatísticos utilizados foram os não paramétricos.

\subsection{Saúde organizacional}

A saúde organizacional avaliada neste estudo é composta por dois fatores, sendo: (I) integração de pessoas e equipes; e (ii) flexibilidade e adaptação demanda externas. Os dados resultantes das respostas para o fator "Integração de pessoas e equipes" são apresentados na Tabela 2. Este fator avaliou a percepção do trabalhador quanto às crenças do empregado de que organização é capaz de estimular compartilhamento dos objetivos organizacionais, a integração de seus membros as suas equipes de trabalho.

Tabela 2 - Integração de pessoas e equipes

\begin{tabular}{l|c|c}
\hline Média do fator & Qtde. & Percentual \\
\hline Média fatorial entre 1 e 2,9 & 21 & $31,8 \%$ \\
Média fatorial entre 3 e 3,9 & 35 & $53,0 \%$ \\
Média fatorial entre 4 e 5 & 10 & $15,2 \%$ \\
\hline
\end{tabular}

Fonte: Dados da pesquisa (2016). 
Percebe-se que a média fatorial entre 3 e 3,9 é a que apresentou resultados de maior representatividade na escala utilizada, na qual 35 (53\%) dos participantes do estudo indicaram que têm dúvida se a organização onde trabalha é capaz de estimular compartilhamento dos objetivos organizacionais, a integração de seus membros às suas equipes de trabalho. Apenas uma minoria representada por $10(15,2 \%)$ têm a percepção positiva quanto esta capacidade da organização.

Os resultados para o fator "Flexibilidade e adaptação demanda externas" avaliou a percepção do trabalhador quanto às crenças do empregado de que a organização possui políticas e procedimentos de trabalho flexíveis e voltados para a adaptação da organização às demandas do ambiente externo. Os resultados são apresentados na Tabela 3.

Tabela 3 - Flexibilidade e adaptação demanda externas

\begin{tabular}{l|c|c}
\hline Média do fator & Qtde. & Percentual \\
\hline Média fatorial entre 1 e 2,9 & 10 & $15,2 \%$ \\
Média fatorial entre 3 e 3,9 & 37 & $56,1 \%$ \\
Média fatorial entre 4 e 5 & 19 & $28,8 \%$ \\
\hline
\end{tabular}

Fonte: Dados da pesquisa (2016).

Para este fator, $37(56,1 \%)$ dos pesquisados demonstram não ter certeza se a organização demonstra flexibilidade nas suas políticas e procedimentos quando da necessidade de adaptação às demandas do ambiente externo. Outros $19(28,8 \%)$ indicaram que esta flexibilidade é perceptível na organização.

Considerando os resultados apresentados para os dois fatores que compõem a EPSaO, no qual $84,8 \%$ dos pesquisados indicaram que não percebem que existe ou têm dúvidas quanto à capacidade de estimular compartilhamento dos objetivos organizacionais, e outros $71,3 \%$ da mesma forma não perceberam que existe ou têm dúvidas quanto a flexibilidade nas políticas e procedimentos organizacionais na adaptação às demandas do ambiente externo. Estes resultados sugerem que a organização em estudo não apresenta um nível de saúde organizacional satisfatório de acordo com a percepção de seus funcionários.

\subsection{Confiança do empregado na organização}

A confiança do empregado na organização foi avaliada neste estudo pela ECEO, a qual é composta por cinco dimensões: (i) promoção do crescimento do empregado; (ii) solidez organizacional; (iii) normas relativas à demissão de empregados; (iv) reconhecimento financeiro organizacional; e (v) padrões éticos.

Os dados resultantes das respostas para a dimensão "promoção do crescimento do funcionário" são apresentados na Tabela 4. Esta dimensão avaliou aspectos associados à promoção do crescimento do funcionário, que se refere a incentivos ao seu crescimento profissional através de alternativas reais e concretas que a empresa proponha, possibilitando ao funcionário que ele visualize seu crescimento em seu trabalho. Para esta dimensão os funcionários participantes da amostra indicaram estar indiferentes, ou seja, para 53\% destes trabalhadores, a promoção do crescimento de empregado parece não ser relevante.

Para outros $24,2 \%$ dos funcionários, esta dimensão tem um aspecto positivo quando se trata de incentivos ao crescimento profissional dos empregados por meio de alternativas concretas e reais propostas pela organização, permitindo aos colaboradores prever seu crescimento naquele contexto de trabalho.

Na dimensão solidez organizacional avaliou-se a estabilidade financeira da empresa, o cumprimento com suas obrigações como, pagar seus funcionários e fornecedores nos dias certos, ou seja, pontualmente, e também engloba a capacidade da empresa de superar crises econômicas. Para esta dimensão, os resultados mostraram que $54,5 \%$ dos participantes da pesquisa são indiferentes. Já outros $27,3 \%$ indicaram uma percepção positiva quanto aos aspectos que compõem a dimensão solidez organizacional. 
Tabela 4 - Dimensões da ECEO

\begin{tabular}{lccc}
\hline \multicolumn{1}{c}{ Denominações } & Percepção & Qtde. & $\%$ \\
\hline \multirow{2}{*}{ Promoção do crescimento do } & Negativa & 15 & $22,7 \%$ \\
empregado & Indiferente & 35 & $53,0 \%$ \\
& Positiva & 16 & $24,2 \%$ \\
\hline \multirow{2}{*}{ Solidez organizacional } & Negativa & 12 & $18,2 \%$ \\
& Indiferente & 36 & $54,5 \%$ \\
& Positiva & 18 & $27,3 \%$ \\
\multirow{2}{*}{ Normas relativas à demissão de } & Negativa & 53 & 80,3 \\
empregados & Indiferente & 13 & $19,7 \%$ \\
& Positiva & 00 & $0,0 \%$ \\
\hline \multirow{2}{*}{ Reconhecimento financeiro } & Negativa & 26 & $39,4 \%$ \\
organizacional & Indiferente & 25 & $37,9 \%$ \\
& Positiva & 15 & $22,7 \%$ \\
\hline \multirow{2}{*}{ Padrões éticos } & Negativa & 5 & $7,6 \%$ \\
& Indiferente & 38 & $57,6 \%$ \\
& Positiva & 23 & $34,8 \%$ \\
\hline
\end{tabular}

Fonte: Dados da pesquisa (2016)

Para a dimensão normas relativas à demissão de empregados na organização, os dados indicaram que grande parte dos pesquisados, $80,3 \%$ corresponde a 53 trabalhadores, têm percepção negativa quanto às normas organizacionais definidas para demissão de trabalhadores, permitindo, ou não, ao empregado prever sua permanência na organização. Cabe destacar que para esta dimensão nenhum trabalhador participante da pesquisa indicou percepção positiva, sugerindo que os aspectos inerentes às normas e políticas de gestão nos processos de demissão não contribuem quando é avaliada a confiança organizacional.

Outra dimensão avaliada foi o reconhecimento financeiro organizacional, a qual avalia o reconhecimento e valorização financeira, principalmente em forma de salário pelos esforços dos funcionários. Para esta dimensão, os dados resultaram em uma percepção negativa de $39,4 \%$, dos pesquisados, indiferente para $37,9 \%$, e positiva para outros $22,7 \%$.

Nesta dimensão, o funcionário avalia a percepção quanto da concessão de aumento salarial é percebida como uma das manifestações de reconhecimento por parte da organização. De acordo com Gomide e Fernandes (2008), esse reconhecimento financeiro beneficia ambas as partes. Diante dos resultados para esta dimensão verifica-se que as políticas de gestão no escopo de reconhecimento financeiro não contribuem para o grau de confiança na organização em estudo.

Para a dimensão padrões éticos, a qual se refere a princípios éticos como honestidade, igualdade, transparência da organização ao divulgar informações responsabilidade, e manutenção de compromissos e respeito. Os resultados indicaram que $57,6 \%$ dos respondentes são indiferentes quando questionados sobre estes padrões éticos. Outros $34,8 \%$ veem como positiva a postura da organização, ou seja, acreditam que tais princípios orientam a relação da organização com seus clientes e empregados ao procurar não prejudicar àqueles com os quais se relaciona.

Considerando os resultados apresentados para as cinco dimensões que compõem a ECEO, a dimensão que apresentou maior percentual para percepção positiva de acordo com os pesquisados foi a dimensão padrões éticos com $34,8 \%$, já para a dimensão normas relativas à demissão de empregados os pesquisados indicaram percepção negativa representada por $80,3 \%$ dos pesquisados. Estes resultados, entre os demais sugerem que a organização em estudo, não apresenta um nível de confiança satisfatório do empregado na organização, de acordo com a percepção de seus funcionários.

\subsection{Resultados além da EPSAO e ECEO}

Buscando ampliar as análises esta seção tem como objetivo apresentar resultados obtidos a partir da aplicação de técnicas estatísticas multivariadas considerando as variáveis utilizadas nas escalas EPSaO e ECEO, bem como, dos dados demográficos da amostra pesquisada. 


\subsubsection{Análise de Correlação nas escalas EPSaO e ECEO}

Com objetivo de verificar o relacionamento entre as dimensões que compunham o instrumento de pesquisa, o qual buscou avaliar a saúde organizacional (EPSaO), foi realizada a correlação entre do is fatores que compõem a referida escala, sendo: (i) integração de pessoas e de equipes; (ii) flexibilidade e adaptação.

De acordo com Field (2009) a análise de correlação compreende em verificar a intensidade da relação por meio do valor do Coeficiente $(\eta)$, e levando o coeficiente de correlação ao quadrado $\left(R^{2}\right)$, se tem o coeficiente de determinação $\left(R^{2}\right)$, o qual é uma medida da quantidade de variação em uma variável que é explicada pela outra. A Tabela 5 apresenta os resultados da correlação de Spearman entre os fatores da EPSaO.

Tabela 5 - Correlação entre os fatores da EPSAO

\begin{tabular}{lllrl}
\hline & & & Fator 1 & Fator 2 \\
\hline Spearman's rho & Fator 1 - Integração de & Correlation Coefficient & 1,000 & \\
& pessoas e equipes & Sig. (2-tailed) & & \\
& & $N$ & 66 & \\
\cline { 2 - 6 } & Fator 2 - Flexibilidade e & Correlation Coefficient &, $670^{* *}$ & 1,000 \\
& adaptação demanda & Sig. (2-tailed) &, 000. & \\
& externas & $N$ & 66 & 66 \\
\hline
\end{tabular}

** Correlation is significant at the 0.01 level (2-tailed). Fonte: Dados da pesquisa (2016).

Analisando a correlação entre os fatores pode-se identificar que o Fator 1 (Integração de pessoas e equipes) tem correlação positiva e intensidade alta com o Fator 2 (Flexibilidade e adaptação de demanda externas) em $(0,670)$. A correlação entre os fatores apresento u o valor $p<0,05$, ou seja, apresentou significância estatística dentro dos parâmetros aceitáveis para a área das ciências sociais aplicadas. Ampliando a análise utilizando o coeficiente de determinação $\left(R^{2}\right)$ conforme propõe Field (2009), 44,89\% da variação do Fator 1 é explicada pela variação do Fator 2 .

Buscou-se também avaliar as correlações de confiança organizacional para as cinco dimensões que compõem a ECEO, sendo: (i) dimensão de promoção de crescimento do empregado; (ii) solidez organizacional; (iii) normas relativas à demissão de empregados; (iv) reconhecimento financeiro organizacional; e (v) padrões éticos.

A Tabela 6 apresenta os resultados da correlação de Spearman entre as dimensões que compõem a ECEO. 
Tabela 6 - Correlação entre as dimensões - ECEO

\begin{tabular}{|c|c|c|c|c|c|c|c|}
\hline & & & 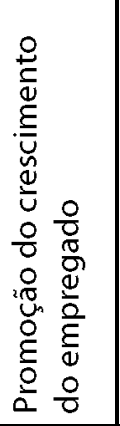 & 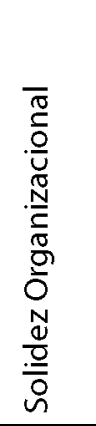 & 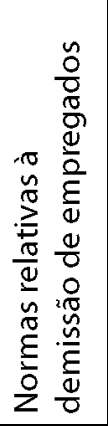 & 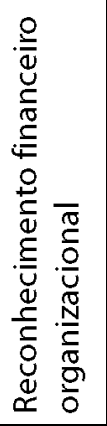 & 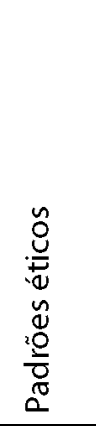 \\
\hline \multirow[t]{6}{*}{$\begin{array}{l}\text { Spearman's } \\
\text { rho }\end{array}$} & $\begin{array}{l}\text { Promoção do } \\
\text { crescimento do } \\
\text { empregado }\end{array}$ & $\begin{array}{l}\text { Correlation Coefficient } \\
\text { Sig. (2-tailed) } \\
N\end{array}$ & $\begin{array}{r}1,000 \\
6 \\
6\end{array}$ & & & & \\
\hline & \multirow[t]{2}{*}{$\begin{array}{l}\text { Solidez } \\
\text { Organizacional }\end{array}$} & $\begin{array}{l}\text { Correlation Coefficient } \\
\text { Sig. (2-tailed) }\end{array}$ & $\begin{array}{r}757^{* * *} \\
, 000 \\
66\end{array}$ & $\begin{array}{r}1,000 \\
66\end{array}$ & & & \\
\hline & & 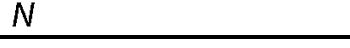 & 66 & 66 & & & \\
\hline & $\begin{array}{l}\text { Normas relativas à } \\
\text { demissão de } \\
\text { empregados }\end{array}$ & $\begin{array}{l}\text { Correlation Coefficient } \\
\text { Sig. (2-tailed) } \\
N\end{array}$ & $\begin{array}{r}-, 280^{*} \\
, 023 \\
66 \\
\end{array}$ & $\begin{array}{r}-, 196 \\
, 114 \\
66 \\
\end{array}$ & $\begin{array}{r}1,000 \\
66 \\
\end{array}$ & & \\
\hline & $\begin{array}{l}\text { Reconhecimento } \\
\text { financeiro } \\
\text { organizacional }\end{array}$ & $\begin{array}{l}\text { Correlation Coefficient } \\
\text { Sig. (2-tailed) } \\
N\end{array}$ & $\begin{array}{r}, 840^{* *} \\
, 000 \\
66\end{array}$ & $\begin{array}{r}788^{* *} \\
, 000 \\
66\end{array}$ & $\begin{array}{r}-, 232 \\
, 061 \\
66\end{array}$ & $\begin{array}{r}1,000 \\
66\end{array}$ & \\
\hline & Padrões éticos & $\begin{array}{l}\text { Correlation Coefficient } \\
\text { Sig. (2-tailed) } \\
N\end{array}$ & $\begin{array}{r}749^{* *} \\
, 000 \\
66\end{array}$ & $\begin{array}{r}669^{* *} \\
, 000 \\
66\end{array}$ & $\begin{array}{r}-, 498^{* *} \\
, 000 \\
66\end{array}$ & $\begin{array}{r}, 780^{* *} \\
, 000 \\
66\end{array}$ & $\begin{array}{r}1,000 \\
. \\
66\end{array}$ \\
\hline
\end{tabular}

**. Correlation is significant at the 0.01 level (2-tailed). Fonte: Dados da Pesquisa (2016).

Analisando a correlação entre as variáveis pode-se identificar que a dimensão Promoção do crescimento do empregado apresenta correlação positiva e de intensidade alta com as dimensões Solidez organizacional $(0,757)$, com o Reconhecimento financeiro organizacional $(0,840)$, e também a dimensão Padrões éticos $(0,749)$. Analisando ainda a dimensão Promoção do crescimento do empregado apresenta correlação negativa com a dimensão normas relativas à demissão de empregados $(-0,280)$.

Ampliando a análise do coeficiente de correlação para o coeficiente de determinação proposta por Field (2009), 57,30\% da variação da dimensão Promoção do crescimento do empregado pode ser explicada pela variação da dimensão Solidez organizacional, $70,56 \%$ da variação da dimensão Reconhecimento financeiro organizacional, e 56,1\% da variação da dimensão Padrões éticos.

Avaliando o coeficiente de correlação resultante entre a dimensão Reconhecimento financeiro organizacional, verifica-se a existência de uma correlação positiva e intensidade alta $(0,780)$, com a dimensão Padrões éticos. Aplicando o coeficiente de determinação, 60,84\% da variação da dimensão Reconhecimento financeiro organizacional pode ser explicada pela variação da variável Padrões éticos.

A correlação entre as dimensões, Normas relativas à demissão de empregados e Padrões éticos apresentou coeficiente de correlação negativo, com intensidade média $(-0,498)$. Diante deste resultado podemos sugerir que a falta de normas quanto ao processo de demissão praticado pela organização pode contribuir de forma negativa na percepção quanto aos padrões éticos avaliados pelo estudo.

Já a correlação entre a dimensão Solidez organizacional apresentou-se positiva de intensidade alta com as dimensões Reconhecimento financeiro organizacional $(0,788)$, e com Padrões éticos $(0,669)$. Ampliando a análise com o coeficiente de determinação (R2), $62 \%$ da variação da dimensão Solidez organizacional podem ser explicadas pela variação da dimensão Reconhecimento financeiro organizacional, e em 44,75\% pela variação da dimensão Padrões éticos. 


\subsubsection{Análise aplicando testes de hipóteses}

Continuando a análise baseada no comportamento dos dados, buscou-se verificar se haviam diferenças entre os grupos, elaborando hipóteses quanto aos fatores e dimensões avaliadas no estudo. Em detrimento a não normalidade dos dados, fez-se uso do teste não paramétrico Mann-Whitney $U$, o qual se aplicada quando se compara dois grupos. A Tabela 7 apresenta o resultado do teste de hipótese desenvolvido.

Tabela 7 - Resultado dos testes de hipóteses

\begin{tabular}{|c|c|c|}
\hline Grupos & Hipóteses & Mann-Whitney U \\
\hline \multirow{2}{*}{$\begin{array}{l}\text { Gênero } \\
\text { EPSaO }\end{array}$} & $\begin{array}{l}\mathrm{H}_{0}: \text { Fator } 1=\text { entre homens e mulheres } \\
\mathrm{H}_{\mathrm{A}}: \text { Fator } 1 \neq \text { entre homens e mulheres }\end{array}$ & Sig. 0,802 \\
\hline & $\begin{array}{l}\mathrm{H}_{0}: \text { Fator } 2=\text { entre homens e mulheres } \\
\mathrm{H}_{\mathrm{A}} \text { : Fator } 2 \neq \text { entre homens e mulheres }\end{array}$ & Sig. 0,887 \\
\hline \multirow{5}{*}{$\begin{array}{l}\text { Gênero } \\
\text { ECEO }\end{array}$} & $\begin{array}{l}\mathrm{H}_{0}: \text { Promoção/crescimento do empregado }=\text { entre homens e mulheres } \\
\mathrm{H}_{\mathrm{A}}: \text { Promoção/crescimento do empregado } \neq \text { entre homens e mulheres }\end{array}$ & Sig. 0,954 \\
\hline & $\begin{array}{l}\mathrm{H}_{0}: \text { Solidez Organizacional }=\text { entre homens e mulheres } \\
\mathrm{H}_{\mathrm{A}}: \text { Solidez Organizacional } \neq \text { entre homens e mulheres }\end{array}$ & Sig. 0,995 \\
\hline & $\begin{array}{l}\mathrm{H}_{0}: \text { Normas relativas à demissão }=\text { entre homens e mulheres } \\
\mathrm{H}_{\mathrm{A}}: \text { Normas relativas à demissão } \neq \text { entre homens e mulheres }\end{array}$ & Sig. 0,015 \\
\hline & $\begin{array}{l}\mathrm{H}_{0}: \text { Reconhecimento financeiro org. }=\text { entre homens e mulheres } \\
H_{A}: \text { Reconhecimento financeiro org. } \neq \text { entre homens e mulheres }\end{array}$ & Sig. 0,959 \\
\hline & $\begin{array}{l}H_{0}: \text { Padrões éticos }=\text { entre homens e mulheres } \\
H_{A}: \text { Padrões éticos } \neq \text { entre homens e mulheres }\end{array}$ & Sig. 0,485 \\
\hline
\end{tabular}

Fonte: Dados da Pesquisa (2016).

Os testes de hipótese para grupo "gênero" na EPSaO buscaram verificar se haviam diferença entre a opinião entre homens e mulheres para ambos os fatores. Para ambos os Fatores os resultados apresentaram $p>0,05$, aceitando assim a hipótese nula $\left(\mathrm{H}_{0}\right)$, indicando que não há diferença estatisticamente significativa entre a opinião de homens e mulheres quando questionados sobre os fatores que compõem o construto saúde organizacional estudado.

Analisando os resultados para o mesmo grupo, com as dimensões que compõem a ECEO para a hipótese envolvendo a dimensão Normas relativas à demissão resultou em Sig. $=0,015$, sendo $p<0,005$, então neste caso rejeita-se $\mathrm{H}_{0}$, ou seja, há diferença entre a opinião dos homens e mulheres para a dimensão analisada. Para as demais hipóteses testadas os valores resultaram em $p>0,05$, indicando a não existência de diferença entre a opinião de homens e mulheres que compuseram a amostra de funcionários pesquisada.

\section{CONSIDERAÇÕES FINAIS}

A preocupação com a avaliação da saúde e confiança organizacional tem ocupado cada vez mais um lugar de destaque no âmbito da gestão das organizações. Por meio de pesquisas, os gestores buscam informações para que possam suportar suas decisões de forma mais adequada na busca pelos resultados organizacionais esperados.

Por meio de uma abordagem quantitativa, com características de pesquisa e descritiva, o presente estudo buscou analisar a saúde e a confiança do empregado na organização considerando a percepção dos trabalhadores. A operacionalização do estudo fez uso da técnica de levantamento (survey) para a coleta de dados e aplicação de técnicas estatísticas bivariadas e multivariadas.

A população estimada foram os 110 funcionários do Laticínio Alto Alegre localizado no município de Verê - PR. A amostra para o estudo foi constituída por 66 funcionários, destes 30 são do gênero feminino e outros 36 do gênero masculino, os quais participaram do estudo por conveniência e aceitação, o que correspondeu $60 \%$ da população estimada. 
Os resultados sobre saúde organizacional evidenciados pela EPSaO, sugerem que a organização estudada não apresenta um nível de saúde organizacional satisfatório de acordo com a percepção de seus funcionários, pois os resultados para os dois fatores que compõem a EPSaO sugerem que $84,8 \%$ dos pesquisados indicaram que não percebem que existe ou tem dúvidas quanto à capacidade de estimular compartilhamento dos objetivos organizacionais, e outros $71,3 \%$ da mesma forma, não perceberam que existe ou têm dúvidas quanto a flexibilidade nas políticas e procedimentos organizacionais na adaptação às demandas do ambiente externo.

Quando avaliada a confiança do empregado na organização por meio da ECEO em suas cinco dimensões, verifica-se que a dimensão que apresentou maior percentual para percepção positiva de acordo com os pesquisados foi a dimensão padrões éticoscom 34,8\%, já para a dimensão normas relativas à demissão de empregados, os pesquisados indicaram percep ção negativa representada por $80,3 \%$ dos pesquisados. Estes resultados, entre os demais, sugerem que a organização em estudo, não apresenta um nível de confiança do empregado na organização satisfatório de acordo com a percepção de seus funcionários.

Buscando ampliar as análises, outros resultados foram obtidos a partir dos construtos utilizados na avaliação da saúde e confiança organizacional indicada pelos funcionários. Os resultados sugerem correlação significativa de intensidade alta entre os dois fatores que compõem a EPSaO. Na correlação das dimensões da escala ECEO após a avaliação das cinco dimensões os resultados obtidos foram que algumas das dimensões apresentaram correlação de intensidade alta com outras dimensões, e algumas dimensões apresentaram correlação negativa de intensidade média, com destaque para a correlação entre a dimensão Promoção do crescimento do empregado que apresenta correlação positiva e de intensidade alta com a dimensão Solidez organizacional $(0,757)$.

Os resultados para testes de hipóteses na variável referente aos fatores da escala EPSaO, ambos os fatores não apresentaram diferenças estatisticamente significativa entre

gêneros. Na análise da escala ECEO o teste de hipótese considerando o mesmo grupo, entre as suas cinco dimensões, apenas a dimensão referente a Normas relativas à demissão de empregados mostrou diferença significativa estatisticamente, entre gêneros.

Considerando os resultad os apresentad os a partir das escalas psicométricas utilizadas (EPSaO e ECEO), as evidências sugerem que a organização em estudo não apresenta um nível de saúde e confiança organizacional satisfatório na opinião dos seus funcionários.

Diante destes achados, este estudo pode contribuir para que a organização, objeto de estudo possa refletir sobre os aspectos e variáveis que compõem os temas pesquisados, e assim promover ações de gestão no âmbito da saúde e confiança organizacional, a partir da percepção dos indivíduos que vivenciam os processos organizacionais.

Como limitação do estudo, destaca-se a sua realização utilizando escalas psicométricas específicas. Outra limitação a ser considerada para o estudo é o corte transversal, sendo que estudos longitudinais poderiam agregar novas contribuições. Ademais, os resultados obtidos são válidos apenas para a amostra estudada em uma única organização, limitando as possíveis generalizações.

\section{REFERÊNCIAS}

BENNIS, W. G. Toward a truly scientific management: the concept of organizational health. General Systems Yearbook, v. 7, p. 269-282, Dec. 1962.

CERVO, A. L.; BERVIAN, P. A.; SILVA, R. Metodologia científica. 6. ed. São Paulo: Person Prentice Hall, 2007.

COTTA, C. M. Confiança e cultura organizacional: um estudo de caso em uma rede de varejo. 2010. $128 \mathrm{f}$.

Dissertação (Mestrado Profissional em Administração) - Faculdades Pedro Leopoldo, Pedro Leopoldo, 2010.

DANCEY, C. P.; REIDY, J. Estatística sem matemática para psicologia. 3. ed. Porto Alegre: Artmed, 2006.

FIELD, A. Descobrindo a estatística usando o SPSS. 2. ed. Porto Alegre: Artmed, 2009. 
FORDYCE, J.K.; WEIL, R. Managing with people: a managers handbook methods.

Reading, MA: Addison Wesley Publishing Company, 1971.

GOMIDE JUNIOR, S.; FERNANDES, M. N. Saúde organizacional. Porto Alegre: Artmed, 2008.

HOSMER, L. Trust: the connecting link between organizational theory and philosophical ethics. Academy of Management Review, Mississipi, v. 20, n. 3, 1995.

KATZ, D.; KAHN, R. L. The social psychology of organizations. New York: Wiley, 1966.

MARTINS, G. A.; THEÓPHILO, C. R. Metodologia da investigação científica para ciências sociais aplicadas. 2. ed. São Paulo: Atlas, 2009.

MELLO, F. A. F. Desenvolvimento das organizações: uma opção integradora. Rio de J aneiro: Livros Técnicos e Científicos, 1978.

MORAES, E. R. Percepção de suporte organizacional e social no trabalho como antecedentes da percepção de saúde da organização. 2007. Dissertação (Mestrado em pós-graduação em psicologia) Universidade Federal de Uberlândia, Uberlândia, 2007.

OLIVEIRA, A. F. Confiança do empregado na organização: impacto dos valores pessoais e organizacionais da justiça organizacional. 2004. Tese (Doutorado em psicologia instituto de psicologia) - Universidade de Brasília, Brasília, 2004.

OLIVEIRA, A. F.; TAMAYO, A. confiança do empregado na organização. Porto Alegre: Artmed, 2008.

OLIVEIRA, J. N.; GOMIDEJUNIOR, S. Percepção de saúde e efetividade organizacionais construção, validação e discriminação das medidas dos constructos. 2009. Dissertação (Mestrado em Psicologia) Universidade Federal de Uberlândia, Uberlândia, 2009.

PASSUELLO, C, B. Confiança e risco em decisões estratégicas: uma análise a partir de elementos do sistema experiencial. 121 f. Dissertação (Mestrado em Administração) - Programa de Pós-Graduação em Administração, Universidade do Vale do Rio dos Sinos, São Leopoldo, 2006.

SCHEIN, E. Organizational psychology. Englewood Cliffs, NJ: Prentice-Hall, 1965.

ZANINI, M. T. Confiança: o principal ativo intangível de uma empresa: pessoas, motivação e construção de valor. Rio de Janeiro: Elsevier, 2007.

ZANINI, M.; LUSK, E.; WOLFF, B. Confiança dentro das organizações da nova economia: uma análise empírica so bre as consequências da incerteza institucional. Revista Contemporânea em Administração, Curitiba, v. 13, n. 1, p. 72-91, jan./mar. 2009. 